\title{
Individual variation of persistent organic pollutants in relation to stable isotope ratios, sex, reproductive phase and oxidative status in Scopoli's shearwaters (Calonectris diomedea) from the Southern Mediterranean
}

\author{
David Costantini ${ }^{\mathrm{a}, \mathrm{b}, *}$, Manrico Sebastiano ${ }^{\mathrm{b}}$, Martina S. Müller ${ }^{\mathrm{c}}$, Igor Eulaers ${ }^{\mathrm{d}}$, Per Ambus ${ }^{\mathrm{e}}$, \\ Govindan Malarvannan ${ }^{\mathrm{f}}$, Adrian Covaci ${ }^{\mathrm{f}}$, Bruno Massa $^{\mathrm{g}}$, Giacomo Dell'Omo ${ }^{\mathrm{h}}$ \\ a UMR 7221, Muséum National d'Histoire Naturelle, 7 rue Cuvier, 75231 Paris Cedex 05, France \\ ${ }^{\mathrm{b}}$ Behavioural Ecology \&' Ecophysiology Group, Department of Biology, University of Antwerp, Universiteitsplein 1, 2610 Wilrijk, Belgium \\ c Graduate School of Environmental Studies, Nagoya University, Nagoya, Japan \\ d Department of Bioscience, Aarhus University, Frederiksborgvej 399, PO Box 358, 4000 Roskilde, Denmark \\ e Department of Geosciences and Natural Resource Management, University of Copenhagen, Øster Voldgade 10, 1350 København K, Denmark \\ ${ }^{\mathrm{f}}$ Toxicological Centre, Department of Pharmaceutical Sciences, University of Antwerp, Universiteitsplein 1, 2610 Wilrijk, Belgium \\ ${ }^{g}$ Department of Agriculture and Forest Sciences, University of Palermo, Palermo, Italy \\ ${ }^{\text {h }}$ Ornis italica, Piazza Crati 15, 00199 Roma, Italy
}

\section{H I G H L I G H T S}

- We quantified the plasma persistent organic pollutants (POPs) in Scopoli's shearwaters.

- Concentrations of most ¿POPs were higher near the end of the breeding season.

- Neither stable isotopes nor body mass explained individual variation in POPs.

- POPs did not predict the probability of each bird being resighted as breeder the following year.

- POPs were weakly associated with markers of antioxidant protection.

\section{A R T I C L E I N F O}

\section{Article history:}

Received 2 February 2017

Received in revised form 2 April 2017

Accepted 3 April 2017

Available online $\mathrm{xxxx}$

Editor: D. Barcelo

\section{Keywords:}

Antioxidants

Contaminants

Isotopes

Oxidative stress
GRAPH ICALABSTRACT
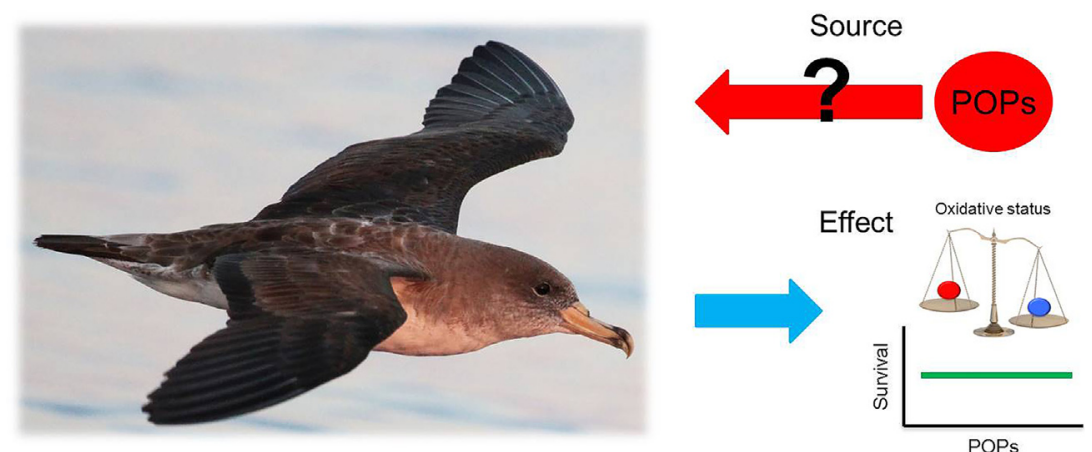
POPs

Seabirds
POPs, but they had similar stable isotope values. There was little evidence for a connection between contaminants and blood-based markers of oxidative balance. None of the contaminants predicted the probability of a bird being resighted as a breeder the following year. Thus, although POPs were present at high concentrations in some individuals, our study suggests little concern regarding POP exposure for this shearwater population.

(C) 2017 Elsevier B.V. All rights reserved.

\section{Introduction}

Persistent organic pollutants (POPs) are chemicals of global environmental concern because they can persist in the environment for a long time, can be dispersed over large geographical areas, are often toxic for diverse biological taxa, and have the tendency to accumulate in organisms and biomagnify through food chains. POPs present in the environment can include legacy (e.g., polychlorinated biphenyls PCBs; organochlorine pesticides OCPs; polybrominated diphenyl ethers PBDEs) and emerging contaminants (e.g., perfluoroalkylatedsubstances PFAs).

At high concentrations, POPs have been shown to impair the health and reproductive fitness of free-living animals (Letcher et al., 2010) and thus may pose a significant hazard to predators feeding at the top of the food chain, such as mammalian carnivores, birds of prey, or seabirds. In seabirds, POPs have been found to negatively impact immunity, the functioning of the endocrine system, regulation of oxidative balance, survival and/or reproductive success (Bustnes et al., 2006; Verreault et al., 2010; Erikstad et al., 2013; Costantini et al., 2014).

To date, little is known about the accumulation of POPs and its consequences for seabirds in the Mediterranean basin. The Barcelona Convention for the protection of the Mediterranean Sea was adopted in 1976, which included the Mediterranean Action Plan and the Mediterranean Marine Pollution Monitoring and Research Programme. However, 40 years later, data remain scarce for background levels in sediments of many pollutants, particularly in the southern areas of the Mediterranean (Gómez-Gutiérrez et al., 2007; Castro-Jiménez et al., 2013). POPs appear to be present at higher concentrations in the Mediterranean Sea than in other oceanic regions (Gómez-Gutiérrez et al., 2007). Previous work has found polychlorinated biphenyls (PCBs) and dichlorodiphenyl ethane plus its main metabolites (DDTs) to be at levels of toxicological concern in some Mediterranean organisms, including predatory fish (Fossi et al., 2004), mussels (Zorita et al., 2007), and seabirds (Roscales et al., 2011). Yet, little is known about the biological consequences of bioaccumulation of pollutants in top predators in this region (Roscales et al., 2011), which is surprising given that top predators are especially susceptible to biomagnification. It is therefore important to identify which POPs are accumulated in southern Mediterranean species, which factors explain their accumulation, and to determine their effects on individual health, particularly in those species of conservation concern.

In this study, we quantified plasma concentrations of 53 legacy POPs (including $\Sigma$ PCBs, $\Sigma$ OCPs and $\Sigma$ PBDEs) in a population of Scopoli's shearwaters (Calonectris diomedea), a seabird species that breeds in the Southern Mediterranean. Although this species is currently listed as 'of Least Concern' by the International Union for the Conservation of Nature, recently the population has been classified as decreasing (International Union for Conservation of Nature and Natural Resources, n.d) (www.iucnredlist.org). Our aims were to (i) characterise the contaminant profile in this seabird species, (ii) assess whether variation in sex, reproductive phase, stable isotope ratios (a proxy of diet) and body mass explains the individual contaminant burden, (iii) test whether mates have similar contaminant burdens, (iv) assess whether the contaminant burden is related to blood-based markers of oxidative damage and antioxidant status and to the resight probability (a proxy of survival/reproductive parameters, Costantini and Dell'Omo, 2015), which is the probability that a given individual is resighted as breeder at the colony the year after blood collection.

\section{Materials and methods}

\subsection{Study species, area and sampling}

The Scopoli's shearwater is a pelagic seabird that breeds in the Mediterranean. Our study population breeds on Linosa ( $35^{\circ} 52^{\prime} \mathrm{N}, 12^{\circ} 52^{\prime} \mathrm{E}$ ), a volcanic island off of Sicily, which holds the second largest colony of shearwaters in the Mediterranean (Massa and Lo Valvo, 1986; Baccetti et al., 2009). The birds breed inside crevices in the lava formations, and are mostly concentrated on the coast of Mannarazza, on the northern side of the island, where the field work has been carried out since 2007. They lay their single egg from the second half of May onwards, and eggs hatch between mid-July and the first week of August. Fledglings typically leave the colony around the end of October. The study nests are numbered and mapped and the breeding birds have been ringed in order to enable individual identification during the yearly monitoring.

Blood samples from breeding birds were collected in October 2013 (near the end of the breeding season; 8 males and 9 females) and in May 2015 (at the beginning of the incubation period; 18 males and 12 females). The dataset included data for 12 pairs (one in 2013 and 11 in 2015). None of the birds were sampled in both years. A sample of venous blood was taken from the leg vein soon after capture and kept in heparinised tubes, which were immediately refrigerated and centrifuged ( 5 min at 4000 RPM) within a few minutes. Both fractions (plasma and erythrocytes) were stored at $-20{ }^{\circ} \mathrm{C}$ while in the field and at $-80^{\circ} \mathrm{C}$ in the laboratory.

\subsection{Persistent organic pollutant analyses}

The analysis of POPs was performed at the Toxicological Centre of the University of Antwerp (Belgium). The analytical protocol was based on the methods described earlier by Eulaers et al. (2011). Plasma samples (median of $370 \mu \mathrm{L}$ and range of $150-550 \mu \mathrm{L}$ depending on plasma volume available) were diluted with $1 \mathrm{~mL}$ of deionised water and $300 \mu \mathrm{L}$ of formic acid, and were then added to the internal standards. Extraction mixtures were sonicated for $20 \mathrm{~min}$ and transferred onto solid phase extraction (SPE) cartridges (OASIS ${ }^{\mathrm{TM}} \mathrm{HLB}$ ) pre-washed with successively $3 \mathrm{~mL}$ of dichloromethane, $3 \mathrm{~mL}$ of methanol and $3 \mathrm{~mL}$ of deionised water. After extraction, the cartridges were eluted with $3 \mathrm{~mL}$ of distilled water onto cartridges containing acidified silica ( $44 \%$ sulphuric acid). The latter cartridges were pre-washed with $2 \mathrm{~mL}$ of hexane and after clean up eluted with $4 \mathrm{~mL}$ of dichloromethane. Resulting eluates were concentrated under a gentle nitrogen flow until dry and redissolved in $100 \mu \mathrm{L}$ of isooctane. Gas chromatography (Agilent GC 6890, Palo Alto, CA, USA) coupled to mass spectrometry (Agilent MS 5973) were used to measure 34 PCB congeners (CB-18, $-28,-31,-44,-47,-49,-52,-66,-70,-74,-87,-95,-99,-101,-105,-110$, $-118,-128,-138,-146,-149,-151,-153,-156,-170,-171,-177,-180$, -183, -187, -194, -196, -199, -203), 7 PBDE congeners (BDE-28, -47, $-99,-100,-153,-154,-183)$, and 12 OCPs, among which dichlorodiphenyltrichloroethane ( $p, p^{\prime}$-DDT), dichlorodiphenyldichloroethylene ( $p, p^{\prime}$ $\mathrm{DDE}$ ), hexachlorobenzene (HCB), trans-and cis-nonachlor (TN and $\mathrm{CN}$ ), trans- and cis-chlordane (TC and $\mathrm{CC}$ ), oxychlordane (OxC), and hexachlorohexanes $(\alpha-, \beta-$, and $\gamma-\mathrm{HCH})$. Most PCB congeners, as well as $p, p^{\prime}$-DDT and $p, p^{\prime}$-DDE were separated using a HT-8 capillary column (30 m*0.22 mm * $0.25 \mu \mathrm{m}$; SGE Analytical Science, Zulte, Belgium), 
with the mass spectrometer operated in electron impact ionization mode. The remaining PCB congeners, as well as HCB, CHLs, HCHs, and PBDEs were separated using a DB-5 capillary column $(30 \mathrm{~m} * 0.25 \mathrm{~mm}$ $* 0.25 \mu \mathrm{m}$; J\&W Scientific, Folsom, CA, USA) and the mass spectrometer operated in electron capture negative ionization mode. Mean \pm SD recoveries of the internal standards CB 143 and BDE 77 were $86 \pm 6 \%$ and $93 \pm 10 \%$, respectively. Plasma concentrations were corrected for average procedural blank values (one blank was included for every 10th plasma sample). The limit of quantification (LOQ) was set for each compound at $3 *$ SD of the procedural blank mean concentration or, for compounds not detected in blanks, set at a 10:1 signal to noise ratio. POPs with concentrations below the LOQ were replaced with a value equal to ( $\mathrm{LOQ} \times$ detection frequency) when the detection frequency (percentage of detection) was $>50 \%$. When the detection frequency for a specific POP was lower than $50 \%$, it was omitted from further data treatment.

\subsection{Oxidative damage and antioxidant analyses}

The d-ROMs assay (Reactive Oxygen Metabolites; Diacron International, Grosseto, Italy) was used to measure plasma oxidative damage metabolites (mostly hydroperoxides) that are generated early in the oxidative cascade. Analyses were done according to manufacturer's instructions as in previous studies (Costantini and Dell'Omo, 2015). Quality controls (Diacron International) were also assessed in each assay. Values of reactive oxygen metabolites have been expressed as $\mathrm{mM}$ of $\mathrm{H}_{2} \mathrm{O}_{2}$ equivalents. Analyses were run in duplicate and the mean coefficients of intra- and inter-assay variation were 3.6 and $6.3 \%$, respectively.

The OXY-Adsorbent test (Diacron International, Grosseto, Italy) was used to quantify the ability of plasma non-enzymatic antioxidants to cope with the in vitro oxidant action of hypochlorous acid ( $\mathrm{HOCl}$; an endogenously-produced oxidant). The procedure is described in detail by Costantini et al. (2011). Analyses were run in duplicate and the mean coefficients of intra- and inter-assay variation were 2.8 and $5.2 \%$, respectively.

The Ransel assay (RANDOX Laboratories, Crumlin, UK) was used to quantify the activity of glutathione peroxidase in haemolysate. This assay is based on the original method of Paglia and Valentine (1967) and analyses were carried out according to Costantini et al. (2011). The kinetic reaction was followed for $3 \mathrm{~min}$ by spectrophotometric reading at $340 \mathrm{~nm}$. A blank reaction was subtracted from the sample absorbance and values were expressed as units $\mathrm{mg}^{-1}$ proteins. Analyses were run in duplicate and the mean coefficients of intra- and interassay variation were 1.4 and $3.3 \%$, respectively.

The Ransod assay (RANDOX Laboratories, Crumlin, UK) was used to quantify the activity of superoxide dismutase in haemolysate. The assay was performed following the manufacturer's instructions (see also Woolliams et al., 1983). The spectrophotometric absorbance was read at $505 \mathrm{~nm}$. Concentrations were calculated using a calibration curve run for each assay and are expressed as units $\mathrm{mg}^{-1}$ proteins. Analyses were run in duplicate and the mean coefficients of intra- and interassay variation were 4.3 and $6.3 \%$, respectively. The concentration of proteins in haemolysates was measured using the Bradford protein assay (Bio-Rad Laboratories, Hercules, USA) with albumin as a reference standard.

\subsection{Stable isotope analyses}

The stable nitrogen $\left(\mathrm{N}:{ }^{14} \mathrm{~N}\right.$ and $\left.{ }^{15} \mathrm{~N}\right)$ and carbon $\left(\mathrm{C}:{ }^{12} \mathrm{C}\right.$ and $\left.{ }^{13} \mathrm{C}\right)$ isotope composition of erythrocytes was measured at the Centre for Permafrost (University of Copenhagen, Denmark). Isotopic values of carbon and nitrogen in erythrocytes are valuable indicators of trophic ecology and, conversely to those from plasma and whole blood, are not affected by uric acid concentration (Quillfeldt et al., 2008). A subsample of 1.03 to $1.95 \mathrm{mg}$ was wrapped into a tin combustion cup, and stable $\mathrm{C}$ and $\mathrm{N}$ isotopes were measured by continuous flow using an elemental analyzer (CE 1110, Thermo Electron, Milan, Italy) coupled to a mass spectrometer (Finnigan MAT Delta PLUS, Thermo Scientific, Bremen, Germany). The instrument was calibrated using secondary isotopic reference materials (SIRM), i.e. sucrose and $\left(\mathrm{NH}_{4}\right)_{2} \mathrm{SO}_{4}$, provided by the International Atomic Energy Agency (IAEA, Vienna, Austria). In house SIRM, i.e. Atropin, was used for the evaluation of analytical performance, showing that the analytical precision was maintained at $0.1 \%$ SD. The ratios of ${ }^{15} \mathrm{~N}:{ }^{14} \mathrm{~N}$ and ${ }^{13} \mathrm{C}:{ }^{12} \mathrm{C}$ of the erythrocytes are reported against those of the international measurement standards Vienna PeeDee Belemnite (vPDB) and atmospheric $\mathrm{N}_{2}$ (AIR), respectively, and are thus expressed as $\delta^{13} \mathrm{C}$ and $\delta^{15} \mathrm{~N}(\%)$.

\subsection{Statistical analyses}

Linear mixed models were performed using the lme4 package in $\mathrm{R}$ (version 3.3.1, R Core Team, 2016), to assess which factors explain variation in total concentration of each type of pollutant in shearwaters (i.e. $\Sigma$ PCBs, $\Sigma$ OCPs, $\Sigma$ PBDEs and $\Sigma$ POPs). Because of collinearity between predictors, we compared the Akaike Information Criterion (AIC) values of six models including: sex; sampling year; sex, sampling year and their interaction; $\delta^{13} \mathrm{C} ; \delta^{15} \mathrm{~N}$; and body mass. In each model, pair was included as a random factor because some birds were mates. For the bestfitting model, we calculated P-values and coefficient estimates of predictors. One male of 2013 and one female of 2015 were excluded from the statistics as Cook's distance testing indicated these to be outliers for $\Sigma$ OCPs and $\Sigma$ PBDEs, respectively. Concentrations of $\Sigma$ PCBs, $\Sigma$ OCPs and $\Sigma$ POPs were log-transformed, while those of $\Sigma$ PBDEs were square-root transformed in order to achieve a normal distribution.

Pearson correlations were used to assess the similarity in contaminant burdens between mates and paired $t$-tests were used to test for sex differences. One pair was excluded from the analysis of $\Sigma$ BDEs because one female was classified as an outlier (see above).

Linear mixed models in the lme4 package in $\mathrm{R}$ were also used to test the association between oxidative balance markers and contaminants, while controlling for sex, bleeding hour, bleeding date, $\delta^{13} \mathrm{C}$ and $\delta^{15} \mathrm{~N}$ because these factors were shown to influence markers of oxidative balance (Costantini, 2014). In each model, pair was included as a random factor. We also tested the interaction between sex and the contaminant class to assess whether the association between antioxidant and pollutant was similar between males and females. We compared males and females for the total concentration of each type of pollutant ( $\Sigma$ PCBs, $\Sigma O C P$, $\Sigma$ PBDEs, $\Sigma$ POPs) and for that of specific pollutants (OxC, HCB, $\beta$-HCH, $p, p^{\prime}$-DDE). SOD was $\log (\mathrm{x}+1)$ transformed to achieve normality of distribution.

Generalized linear mixed models (glmer in package lme4) with a binomial error distribution and a logit link function were used to test the effects of the total concentrations of each class of contaminants ( $\Sigma \mathrm{PCBS}$, $\Sigma O C P$, $\Sigma$ PBDEs, $\Sigma$ POPs) and of specific contaminants (OxC, HCB, $\beta-$ $\mathrm{HCH}, p, p^{\prime}$-DDE) on the individual probability to be resighted at the colony the next year. In each model, sex and its interaction with the class of contaminants were also included; pair and year were included as random factors.

\section{Results}

Concentrations of detectable polychlorinated biphenyls, organochlorine pesticides and polybrominated diphenyl ethers are reported in Table 1. The PCB congeners CB-18, $-28,-31,-44,-47,-49,-52,-66$, $-70,-74,-87,-95,-101,-110,-149$ and -151 were present below the LOQ in all individuals, hence they were not further considered in the statistical analyses and also not discussed further in this manuscript. Among POPs, $\alpha-\mathrm{HCH}, \gamma-\mathrm{HCH}$, and BDE-28 and -183 were undetectable in $5,10,1$ and 1 out of 47 shearwaters, respectively. $\Sigma$ PCB concentrations were the highest of all POPs measured in the investigated samples, with a percentage contribution for each shearwater ranging from 53.0 
Table 1

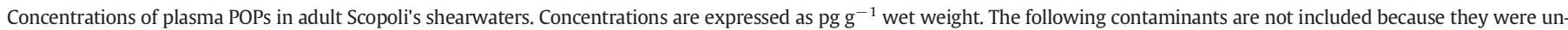

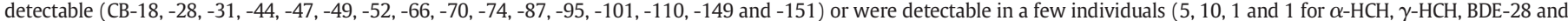
BDE-183, respectively). Sample sizes are 8 males and 9 females in 2013 and 18 males and 12 females in 2015, respectively.

\begin{tabular}{|c|c|c|c|c|c|c|c|c|c|c|}
\hline \multirow[t]{2}{*}{ Contaminant } & \multirow[t]{2}{*}{ LOQ (pg/mL) } & \multirow[t]{2}{*}{ Year } & \multicolumn{4}{|l|}{ Female } & \multicolumn{4}{|l|}{ Male } \\
\hline & & & Mean & Median & Min & Max & Mean & Median & Min & Max \\
\hline \multirow[t]{2}{*}{ CB-99 } & \multirow[t]{2}{*}{4} & 2013 & 692 & 475 & 273 & 1898 & 731 & 467 & 244 & 2433 \\
\hline & & 2015 & 383 & 302 & 51 & 1251 & 232 & 162 & 60 & 807 \\
\hline \multirow[t]{2}{*}{ CB-105 } & 4 & 2013 & 541 & 386 & 268 & 1236 & 574 & 406 & 192 & 1596 \\
\hline & & 2015 & 247 & 244 & 30 & 661 & 160 & 105 & 58 & 533 \\
\hline CB-118 & 2 & 2013 & 1743 & 1316 & 878 & 3628 & 2039 & 1371 & 711 & 5786 \\
\hline & & 2015 & 846 & 854 & 201 & 1895 & 629 & 439 & 233 & 2144 \\
\hline CB-128 & 2 & 2013 & 1240 & 1013 & 536 & 2833 & 1569 & 886 & 396 & 5506 \\
\hline & & 2015 & 763 & 543 & 94 & 3187 & 448 & 277 & 139 & 1744 \\
\hline CB-138 & 2 & 2013 & 13,805 & 10,024 & 5510 & 33,767 & 16,322 & 9340 & 4456 & 57,067 \\
\hline & & 2015 & 7679 & 5700 & 1203 & 29,602 & 4819 & 2963 & 1677 & 18,014 \\
\hline CB-146 & 2 & 2013 & 2214 & 1779 & 930 & 4910 & 2416 & 1646 & 860 & 7691 \\
\hline & & 2015 & 1170 & 954 & 235 & 4113 & 743 & 522 & 296 & 2475 \\
\hline CB-153 & 2 & 2013 & 24,796 & 25,900 & 8230 & 44,125 & 28,862 & 16,767 & 8133 & 78,174 \\
\hline & & 2015 & 11,810 & 9618 & 2140 & 39,359 & 8431 & 5665 & 2498 & 28,407 \\
\hline CB-156 & 2 & 2013 & 914 & 845 & 384 & 1425 & 1084 & 715 & 296 & 2660 \\
\hline & & 2015 & 391 & 425 & 68 & 762 & 311 & 217 & 94 & 990 \\
\hline CB-170 & 2 & 2013 & 7775 & 8971 & 1864 & 16,899 & 8170 & 4490 & 2226 & 20,274 \\
\hline & & 2015 & 3747 & 2920 & 559 & 11,725 & 2853 & 1681 & 747 & 7371 \\
\hline CB-171 & 2 & 2013 & 780 & 752 & 197 & 1570 & 862 & 463 & 248 & 2524 \\
\hline & & 2015 & 425 & 290 & 45 & 1765 & 279 & 154 & 79 & 952 \\
\hline CB-177 & 2 & 2013 & 171 & 124 & 74 & 449 & 132 & 95 & 61 & 410 \\
\hline & & 2015 & 92 & 78 & 19 & 232 & 57 & 33 & 23 & 405 \\
\hline CB-180 & 2 & 2013 & 22,231 & 22,575 & 5068 & 50,311 & 22,580 & 12,646 & 5901 & 58,861 \\
\hline & & 2015 & 9812 & 7812 & 1663 & 29,315 & 7763 & 4643 & 1984 & 18,746 \\
\hline CB-183 & 2 & 2013 & 3657 & 4224 & 828 & 8117 & 3728 & 2029 & 1092 & 9258 \\
\hline & & 2015 & 1692 & 1291 & 258 & 5699 & 1250 & 753 & 327 & 3485 \\
\hline CB-187 & 2 & 2013 & 3330 & 2832 & 1277 & 8157 & 3381 & 2023 & 1141 & 13,577 \\
\hline & & 2015 & 2193 & 1402 & 294 & 9181 & 1154 & 735 & 424 & 3300 \\
\hline CB-194 & 2 & 2013 & 1991 & 2158 & 314 & 3711 & 1720 & 1031 & 517 & 4951 \\
\hline & & 2015 & 761 & 604 & 167 & 2095 & 709 & 419 & 172 & 1676 \\
\hline CB-196/203 & 2 & 2013 & 1824 & 1794 & 291 & 3414 & 1525 & 909 & 521 & 4205 \\
\hline & & 2015 & 703 & 557 & 141 & 1854 & 634 & 385 & 154 & 1605 \\
\hline CB-199 & 2 & 2013 & 592 & 661 & 186 & 1087 & 604 & 376 & 203 & 2344 \\
\hline & & 2015 & 423 & 272 & 70 & 1491 & 284 & 175 & 83 & 1077 \\
\hline$\sum \mathrm{PCBS}$ & & 2013 & 88,296 & 88,899 & 28,149 & 161,256 & 96,299 & 54,650 & 27,488 & 266,405 \\
\hline & & 2015 & 43,136 & 34,318 & 7238 & 144,188 & 30,758 & 18,951 & 9167 & 91,956 \\
\hline $\mathrm{HCB}$ & 5 & 2013 & 731 & 633 & 182 & 1264 & 971 & 975 & 503 & 1572 \\
\hline & & 2015 & 899 & 964 & 287 & 1549 & 466 & 411 & 90 & 984 \\
\hline $\mathrm{OxC}$ & 2 & 2013 & 116 & 106 & 56 & 255 & 137 & 107 & 59 & 336 \\
\hline & & 2015 & 112 & 87 & 41 & 380 & 58 & 51 & 19 & 150 \\
\hline $\mathrm{CC}$ & 2 & 2013 & 4 & 4 & 1 & 11 & 7 & 8 & 1 & 14 \\
\hline & & 2015 & 8 & 9 & 1 & 12 & 4 & 2 & 1 & 24 \\
\hline $\mathrm{CN}$ & 2 & 2013 & 19 & 16 & 10 & 26 & 24 & 23 & 13 & 34 \\
\hline & & 2015 & 35 & 31 & 11 & 77 & 18 & 13 & 7 & 83 \\
\hline TC & 2 & 2013 & 51 & 46 & 23 & 96 & 54 & 59 & 30 & 80 \\
\hline & & 2015 & 35 & 36 & 13 & 66 & 23 & 22 & 13 & 37 \\
\hline $\mathrm{TN}$ & 2 & 2013 & 792 & 748 & 336 & 1567 & 871 & 683 & 387 & 2373 \\
\hline & & 2015 & 658 & 537 & 143 & 1728 & 369 & 313 & 176 & 877 \\
\hline$\beta-\mathrm{HCH}$ & 5 & 2013 & 43 & 42 & 23 & 76 & 47 & 53 & 11 & 70 \\
\hline & & 2015 & 35 & 33 & 20 & 51 & 18 & 15 & 5 & 40 \\
\hline$p, p^{\prime}-\mathrm{DDT}$ & 10 & 2013 & 410 & 213 & 110 & 931 & 587 & 268 & 76 & 2931 \\
\hline & & 2015 & 238 & 204 & 10 & 668 & 168 & 112 & 10 & 663 \\
\hline$p, p^{\prime}-\mathrm{DDE}$ & 10 & 2013 & 19,182 & 8516 & 5483 & 76,403 & 37,861 & 10,596 & 5261 & 228,852 \\
\hline & & 2015 & 12,287 & 5582 & 1074 & 56,996 & 6770 & 3997 & 1448 & 34,254 \\
\hline$\sum \mathrm{OCPS}$ & & 2013 & 21,349 & 10,469 & 6635 & 79,487 & 40,562 & 12,629 & 6553 & 236,065 \\
\hline & & 2015 & 14,317 & 7626 & 1608 & 59,535 & 7896 & 5045 & 1868 & 36,099 \\
\hline BDE-47 & 2 & 2013 & 10 & 10 & 3 & 20 & 18 & 18 & 11 & 28 \\
\hline & & 2015 & 290 & 18 & 2 & 3289 & 14 & 9 & 2 & 63 \\
\hline BDE-99 & 2 & 2013 & 15 & 15 & 10 & 25 & 19 & 16 & 8 & 42 \\
\hline & & 2015 & 401 & 21 & 2 & 4598 & 9 & 6 & 2 & 34 \\
\hline BDE-100 & 2 & 2013 & 14 & 10 & 8 & 33 & 24 & 17 & 9 & 49 \\
\hline & & 2015 & 105 & 21 & 2 & 933 & 10 & 6 & 2 & 52 \\
\hline BDE-153 & 2 & 2013 & 17 & 12 & 6 & 47 & 24 & 22 & 10 & 40 \\
\hline & & 2015 & 108 & 17 & 2 & 1119 & 15 & 10 & 2 & 62 \\
\hline BDE-154 & 2 & 2013 & 10 & 6 & 1 & 33 & 18 & 13 & 8 & 33 \\
\hline & & 2015 & 68 & 10 & 1 & 679 & 6 & 1 & 1 & 58 \\
\hline$\sum$ PBDEs & & 2013 & 66 & 62 & 29 & 123 & 102 & 94 & 67 & 159 \\
\hline & & 2015 & 982 & 83 & 8 & 10,751 & 53 & 34 & 8 & 266 \\
\hline$\sum \mathrm{POPS}$ & & 2013 & 109,711 & 98,747 & 37,622 & 219,026 & 136,964 & 67,377 & 34,140 & 502,628 \\
\hline & & 2015 & 58,435 & 43,078 & 8853 & 203,977 & 38,708 & 24,875 & 11,058 & 128,154 \\
\hline
\end{tabular}


to $92.4 \%$. The percentage contribution of $\Sigma$ OCPs ranged between 7.6 and $47 \%$, while that of $\Sigma$ PBDEs ranged between $<1 \%$ and $22.1 \%$. The congener CB-153 (28.4\% of $\Sigma$ PCBs) was the predominant PCB congener, followed by CB-180 (24.2\%) and -138 (16.5\%). p, p'-DDE was the predominant OCP compound, with a percentage contribution of $90 \%$. Of the analysed PBDEs, the predominant compounds were BDE-99 (37\%) and -47 (28\%).

The best-fitting model based on AIC values showed that sampling year was the main predictor of variation in $\Sigma$ PCBs, $\Sigma$ OCPs and $\Sigma$ POPs (Table 2). Near the end of the breeding season (2013 sampling season), concentrations of $\Sigma$ PCBs (coefficient estimate \pm standard error: -0.42 $\pm 0.10, \mathrm{P}=0.00011), \Sigma \mathrm{OCPs}(-0.30 \pm 0.11, \mathrm{P}=0.0081)$ and $\Sigma \mathrm{POPs}$ $(-0.42 \pm 0.10, \mathrm{P}=0.00019)$ were significantly higher than at the beginning of incubation (2015 sampling season; Table 1). But for 2 PBDEs, the best-fitting model included the interaction between sex and sampling year (Table 2). We therefore tested the effect of sex on $\Sigma$ PBDE separately for the two years of sampling. In 2013, ¿PBDEs were higher in males than females (coefficient estimate \pm standard error: $-2.07 \pm$ $0.82, \mathrm{P}=0.024)$, while in 2015 IPBDEs were higher in females than males $(3.25 \pm 1.05, \mathrm{P}=0.013)$ (Table 1$)$. Both $\delta^{13} \mathrm{C}$ and $\delta^{15} \mathrm{~N}$ were not significantly associated with any contaminant category (Fig. 1 ).

The concentrations of contaminants in females were not correlated with those of their mates for $\Sigma \mathrm{PCBS}(r=0.48$; P $=0.12)$, $\Sigma$ OCPs $(r=$ $0.16 ; \mathrm{P}=0.62), \Sigma$ PBDEs $(r=0.07 ; \mathrm{P}=0.83)$ and $\Sigma$ POPs $(r=$ $0.46, \mathrm{P}=0.13$ ) (Fig. 2). Females had higher concentrations of $\Sigma$ PBDEs $(t=2.5 ; \mathrm{P}=0.031)$ than their mates, while concentrations of $\Sigma$ PCBs $(P=0.053), \Sigma O C P s(P=0.085)$ and $\Sigma P O P s(P=0.057)$ were marginally, but not significantly higher in females than in their mates. Males and females had similar $\delta^{13} \mathrm{C}$ and $\delta^{15} \mathrm{~N}$ (Table 3 ). $\delta^{13} \mathrm{C}$ of males was not correlated with that of females $(r=0.32, \mathrm{P}=$ 0.31 ), while there was a tendency for $\delta^{15} \mathrm{~N}$ to be positively correlated with that of females $(r=0.51, \mathrm{P}=0.085)$.

No contaminant class was significantly associated with variation in plasma reactive oxygen metabolites or in the activity of GPX in red blood cells. Isotope ratios were also not significantly associated with plasma reactive oxygen metabolites nor with GPX. Plasma nonenzymatic antioxidant capacity was significantly higher in those birds having a higher concentration of $\mathrm{OxC}$ (coefficient estimate \pm standard error: $0.22 \pm 0.08, P=0.009$ ), but it was no longer significant after the exclusion of one outlier. Plasma non-enzymatic antioxidant capacity was significantly higher in those birds having higher $\delta^{13} \mathrm{C}(9.3 \pm 3.4$, $\mathrm{P}=0.01)$ and in birds that were blood-sampled later in the day $(0.19 \pm 0.09, \mathrm{P}=0.04)$. As for the activity of SOD in red blood cells, there was a significant interaction between sex and $\beta-\mathrm{HCH}$ $(P=0.004)$ or $\mathrm{HCB}(\mathrm{P}=0.016)$. In males, SOD was not significantly associated with either $\beta$-HCH or HCB. But in females, the SOD activity was higher in those individuals having higher $\beta-\mathrm{HCH}$ (coefficient estimate \pm standard error: $0.008 \pm 0.002, \mathrm{P}=0.006$ ) or $\mathrm{HCB}$ $(0.0002 \pm 0.00007, \mathrm{P}=0.016)$ (Fig. 3 ). All other predictors were not significant.

Finally, none of the contaminant classes predicted the probability of each bird being resighted at the colony the next year (all $\mathrm{P} \geq 0.22$ ).

Table 2

Akaike Information Criterion values of linear mixed models performed to assess which factors explained variation in plasma concentrations of pollutants in adult Scopoli's shearwaters. Values in bold type refer to the best-fitting models.

\begin{tabular}{lllll}
\hline Model & $\sum$ PCBs & $\sum$ OCPS & $\sum$ PBDEs & $\sum$ POPs \\
\hline Sex & 48.2 & 49.0 & 238.3 & 50.4 \\
Sampling year & $\mathbf{3 5 . 8}$ & $\mathbf{4 6 . 4}$ & 237.3 & $\mathbf{3 9 . 5}$ \\
Sex + sampling year + sex $\times$ sampling & 42.8 & 51.0 & $\mathbf{2 2 8 . 6}$ & 45.7 \\
$\quad$ year & & & & \\
$\delta^{13} \mathrm{C}$ & 51.0 & 55.0 & 241.5 & 53.6 \\
$\delta^{15} \mathrm{~N}$ & 48.2 & 54.8 & 240.4 & 51.1 \\
Body mass & 59.7 & 62.7 & 248.8 & 62.1 \\
\hline
\end{tabular}

\section{Discussion}

\subsection{Comparison of contaminant profile with other studies on marine birds}

In comparison with studies of plasma POPs in other marine bird species, the Scopoli's shearwater population in this study has moderately high levels of most contaminants, with some PCB and OCP concentrations present at levels suggested to cause biological effects in other bird species (e.g., snow petrel Pagodroma nivea in Tartu et al., 2015a; black-legged kittiwake Rissa tridactyla in Tartu et al., 2015b). Our observed PCB or OCP concentrations were slightly lower than those reported for other populations of Scopoli's shearwater breeding in the northern (Balearic and Hyeres) or southeast (Crete) Mediterranean (Roscales et al., 2011). On the other hand, concentrations of either PCBs or DDE measured in species breeding in the Mediterranean (e.g. Mediterranean shearwater Puffinus yelkouan and Cory's shearwater Calonectris borealis), or in the Atlantic (e.g. as Cape Verde shearwater Calonectris edwardsii, Cory's shearwater Calonectris borealis, Cape Verde little shearwater Puffinus boydi and Little shearwater Puffinus baroli), were similar or lower than those measured in our population (Roscales et al., 2011). A comparison with other marine species breeding at different latitudes (e.g., poles or tropics) shows that concentrations of several contaminants analysed in Scopoli's shearwaters were around 2 to 1000 times higher (depending on the contaminant) than in the snow petrel during the incubation period in the Antarctic (Tartu et al., 2015a), in the Black-legged kittiwake during the incubation period in Svalbard (Tartu et al., 2015b), in the Eurasian oystercatcher Haematopus ostralegus during the incubation period near the river Elbe (Schwemmer et al., 2015), in the common eider Somateria mollissima during the incubation period in Svalbard (Fenstad et al., 2016) or in the Magnificent frigatebird Fregata magnificens during the chick rearing period in French Guiana (Sebastiano et al., 2016). Compared to studies done on the highly contaminated Glaucous gull Larus hyperboreus (Verboven et al., 2010) and Great skua Stercorarius skua (Leat et al., 2013), plasma levels of POPs in shearwaters were much lower. However, some shearwater individuals had concentrations of some POPs (e.g., CB-153, DDE) that were in the range found for both the Glaucous gull (Verboven et al., 2010) and the Great skua (Leat et al., 2013), suggesting individual variation in risk exposure.

\subsection{Sources of exposure and individual variation}

A recent assessment of levels of PCBs, DDT and its metabolites, and HCB in Mediterranean sediments, found that hot spots for these contaminants are usually located along the northern coasts, while sites close to Linosa Island (one in Sicily and two in Tunisia) have lower levels of these contaminants (Gómez-Gutiérrez et al., 2007). Many POPs included in the Stockholm Convention are no longer produced in developed countries, but they still represent a potential hazard for wildlife because of their long-term persistence in the environment (e.g., PCBs, DDT; Helander et al., 2008; Johansson et al., 2011). In addition, species that migrate between geographically distant breeding and wintering areas may be exposed to recent sources of certain POPs if they spend part of the year in countries where these compounds have not been completely banned or are being used illegally. Shearwaters breeding on Linosa Island overwinter along the coasts of western Africa (Müller et al., 2014). Given the continued widespread use of pesticides for malaria or pest species control (Asogwa and Dongo, 2009; Northern Presbyterian Agricultural Services, 2012; Jepson et al., 2014), bioaccumulation of OCPs in wintering areas might contribute to the observed OCP concentrations recorded in shearwaters in the Linosa breeding area if these are released from adipose tissue when fat is metabolized during the breeding season (Nordstad et al., 2012). OCPs were actually lower in 2015 sampling, which was carried out after the start of egg incubation, which occurs 2-3 months after birds are back from western Africa (Müller et al., 2014). Release of POPs from adipose tissue at the 

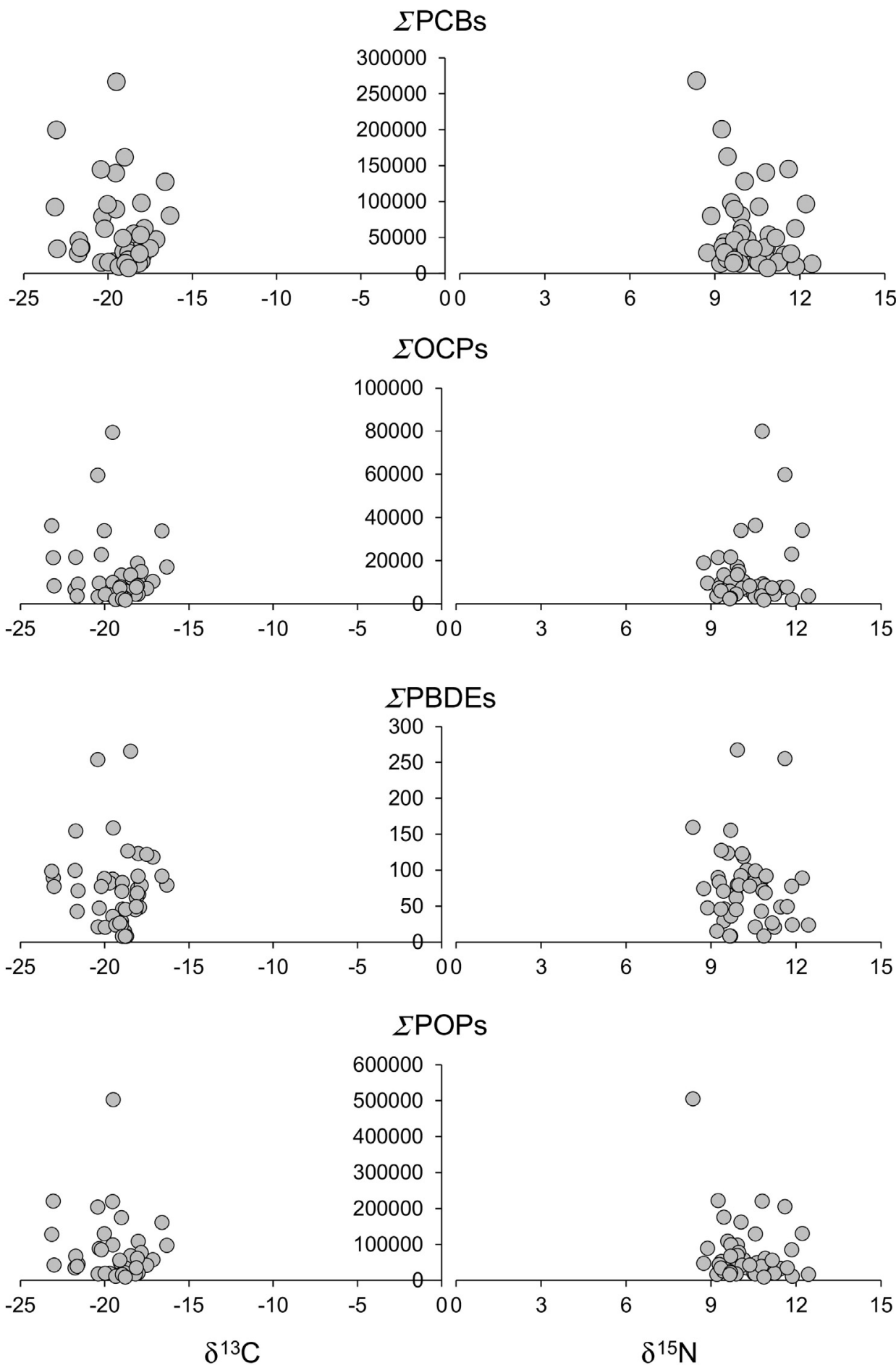

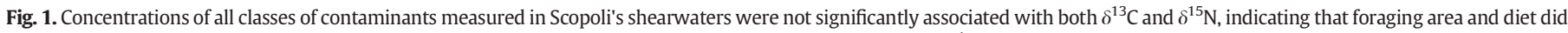
not explain variation in individual contaminant burden. Concentrations of contaminants are expressed as pg g ${ }^{-1}$ wet weight.

end of the breeding season as previously suggested for other seabirds (Nordstad et al., 2012) could account for the annual differences in POP concentrations as body mass of males is lower near the end of the breeding season than at the beginning of the incubation. However, individual contaminant burden was not associated with individual body mass. One explanation might be that body mass also includes the contribution of muscles and skeletal size, making it a poor indicator of body fat dynamics. A longitudinal study with collection of multiple blood samples over the breeding season would help clarify the extent to which release of contaminants from fat explains individual variation in plasma levels.

Our data show that at the beginning of incubation, $\delta^{15} \mathrm{~N}$ in erythrocytes (reflecting dietary habits over 3-4 weeks prior to blood sampling) was higher than near the end of the breeding season (Table 3 ), implying that shearwaters feed on fish from a higher trophic level (e.g., predators) at the beginning of breeding. Although fish from higher trophic levels tend to accumulate more POPs than do fish from lower trophic levels, POPs were higher in shearwaters sampled near the end 

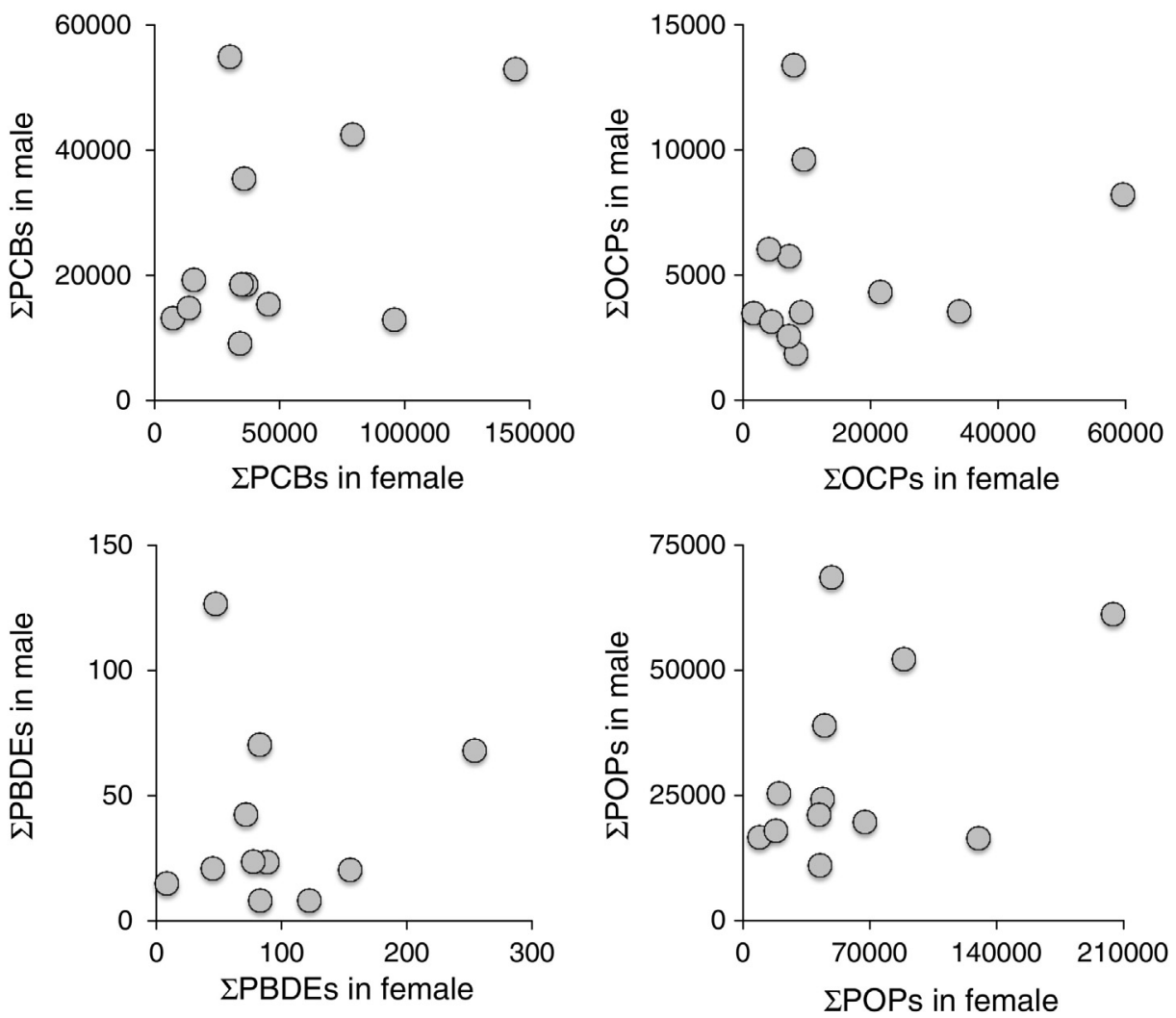

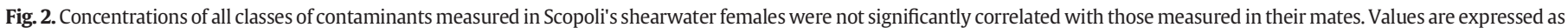
$\mathrm{pg} \mathrm{g}^{-1}$ wet weight.

of the breeding season. However, analyses at the individual level did not show any significant covariation between POPs and $\delta^{15} \mathrm{~N}$. Foraging area rather than prey type might explain variation in POP levels. For example, Linosa Island, as well as the nearby Lampedusa Island, does not have any sewage treatment plants and any locally produced sewage is discharged directly into the sea. The presence of a local source of exposure to both PCBs and OCPs in Linosa was previously identified by a study on contaminant accumulation in mussels (Scarpato et al., 2010). However, $\delta^{13} \mathrm{C}$ (reflecting foraging area over 3-4 weeks prior to blood sampling) was not significantly associated with any class of POPs, probably because POP exposure was similar among the foraging areas of shearwaters.

Our data also show that males and females had similar concentrations of $\Sigma$ PCBs, $\Sigma$ OCPs and $\Sigma$ POPs, irrespective of whether they were sampled soon after, or many months after, egg-laying was completed. $\Sigma$ PBDEs were higher in females soon after the completion of egglaying. It might be that males and females accumulate different amounts of PBDEs in their wintering areas, which were shown to differ between

Table 3

Mean and standard error of blood-based markers of oxidative balance, isotopes and body mass.

\begin{tabular}{lll}
\hline & Male & Female \\
\hline ROMs 2015 (mM H $\mathrm{O}_{2}$ equivalents) & $0.48 \pm 0.02$ & $0.23 \pm 0.04$ \\
SOD 2015 (units $\mathrm{mg}^{-1}$ proteins) & $0.40 \pm 0.03$ & $0.40 \pm 0.05$ \\
$\mathrm{GPX} \mathrm{2015}$ (units $\mathrm{mg}^{-1}$ proteins) & $0.20 \pm 0.01$ & $0.30 \pm 0.03$ \\
OXY 2015 (mM HOCl neutralised) & $202 \pm 7$ & $200 \pm 8$ \\
$\delta^{13} \mathrm{C} 2013$ (ratios of 13C:12C, \%o) & $-19.0 \pm 0.8$ & $-18.7 \pm 0.4$ \\
$\delta^{13} \mathrm{C} 2015$ & $-19.4 \pm 0.3$ & $-19.7 \pm 0.5$ \\
$\delta^{15} \mathrm{~N} 2013$ (ratios of 15N:14N, \%。) & $9.6 \pm 0.2$ & $9.6 \pm 0.2$ \\
$\delta^{15} \mathrm{~N} 2015$ & $10.6 \pm 0.2$ & $10.6 \pm 0.3$ \\
Body mass 2013 (grams) & $620 \pm 24$ & $559 \pm 14$ \\
Body mass 2015 & $692 \pm 9$ & $524 \pm 11$
\end{tabular}

sexes (Müller et al., 2014). Previous work on oviparous species like seabirds or sea turtles showed that females may deposit POPs into their eggs, which is thought to be an important route through which females may detoxify (Verboven et al., 2009; Stewart et al., 2011). Our data do not appear to support this way of detoxification as being important in Scopoli's shearwaters.

\subsection{Association of contaminant burden to health and fitness-related variables}

Concentrations of POPs did not appear to cause any short-term detrimental effects on the birds. Neither oxidative damage nor resight probability were associated with any of the analysed classes of POPs. As with antioxidants, significant associations were only found for SOD and two classes of POPs $(\beta-\mathrm{HCH}$ and $\mathrm{HCB})$ in females only. Antioxidant molecules are important for the protection of cells against oxidative damage, whose accumulation may negatively impact reproductive fitness (Costantini, 2014). A recent meta-analysis showed that oxidative stress is a unifying mechanism underlying the toxicity of anthropogenic pollution including heavy metals, polycyclic aromatic hydrocarbons, or nitrogen-oxides (Isaksson, 2010). Although this meta-analysis showed that the effect size for SOD was moderate, previous mechanistic work showed that contaminants like HCB may increase free radical production and oxidative stress (Addae et al., 2013). Overall, our data suggest that POP concentrations in shearwaters did not have a strong impact on the regulation of blood oxidative balance or, generally, on the health status of birds.

No class of POPs was associated with the probability of shearwaters being resighted the next year as breeders. Moreover, all the birds sampled for this study successfully raised their offspring. Our results are in line with a general lack of association between POPs and demographic traits previously found in black-legged kittiwakes in the year after blood sampling (Goutte et al., 2015). However, we cannot exclude 


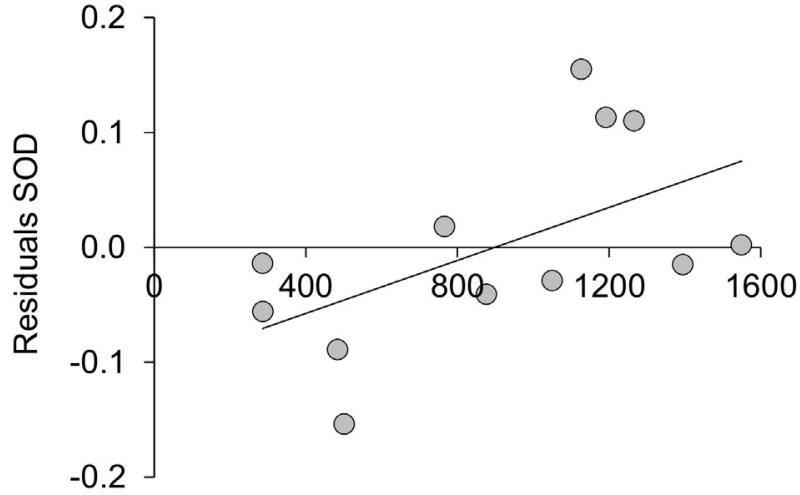

$\beta$-hexachlorohexane (pg g ${ }^{-1}$ wet weight)

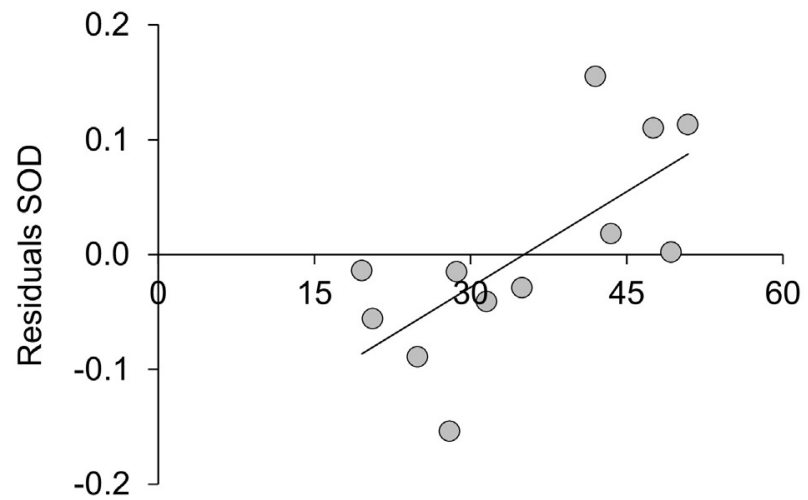

Hexachlorobenzene (pg g $\mathrm{g}^{-1}$ wet weight)

Fig. 3. Scopoli's shearwater females with higher concentrations of $\beta-\mathrm{HCH}$ or $\mathrm{HCB}$ in plasma had a higher activity of SOD in red blood cells (values of SOD are shown as residuals from a model including pair, sampling hour, sampling date, $\delta^{13} \mathrm{C}$ and $\left.\delta^{15} \mathrm{~N}\right)$.

that our cross-sectional approach is not sensitive enough to detect any effects. Although all the birds were adults, we do not know the exact age of each individual, implying that lifetime accumulation history would differ. Repeated sampling from the same individuals can reveal the extent to which pollutants accumulate in individuals across years and how cumulative exposure impinges on reproduction and survival.

\section{Conclusions}

Our work showed that $\Sigma$ PCB concentrations were the highest of all POPs measured and that concentrations of contaminants differed between early incubation and late breeding season. Stable isotope values were not significantly associated with concentrations of contaminants, indicating that diet or foraging area was only weakly associated with individual contaminant burden. This is further supported by a comparison of mates, which had similar stable isotope values, but differed for the concentrations of contaminants. Although concentrations of most contaminant classes tended to be higher near the end of the breeding season (when fat reserves were consumed with consequent release of contaminants into the bloodstream) than at the beginning of the incubation period, individual body mass was not significantly associated with the individual contaminant burden. Although levels of some POPs occurred at high concentrations in some individuals, our study suggests little concern of POP exposure for the health of this shearwater population because they were generally not associated with bloodbased markers of oxidative status and the probability of each bird being resighted as breeder at the colony the next year. Further studies using a longitudinal approach with multiple sampling over the breeding season from the same individuals will help to clarify the dynamics of POPs in this shearwater population.

\section{Acknowledgments}

Research permit was issued by the Regione Siciliana. Research permit n 246/14 was issued by the Regione Siciliana, Assessorato Risorse Agricole e Alimentari. Some part of the study was carried out under the LIFE11 NAT/IT/000093 'Pelagic Birds'. DC and MS were supported by the Research Foundation of Flanders. Ornis italica supported the fieldwork. We thank two anonymous reviewers that provided valuable comments on our manuscript.

\section{References}

Addae, C., Cheng, H., Martinez-Ceballos, E., 2013. Effect of the environmental pollutant hexachlorobenzene $(\mathrm{HCB})$ on the neuronal differentiation of mouse embryonic stem cells. Int. J. Environ. Res. Public Health 10, 5244-5256.

Asogwa, E.U., Dongo, L.N., 2009. Problems associated with pesticide usage and application in Nigerian cocoa production: a review. Afr. J. Agric. Res. 4, 675-683.

Baccetti, N., Capizzi, D., Corbi, F., Massa, B., Nissardi, S., Spano, G., Sposimo, P., 2009. Breeding shearwaters on Italian islands: population size, island selection and co-existence with their main alien predator, the black rat. Riv. Ital. Ornitol. 78, 83-100.

Bustnes, J.O., Tveraa, T., Henden, J.A., Varpe, Ø., Janssen, K., Skaare, J.U., 2006. Organochlorines in Antarctic and Arctic avian top predators: a comparison between the south polar skua and two species of northern hemisphere gulls. Environ. Sci. Technol. 40, 2826-2831.

Castro-Jiménez, J., Berrojalbiz, N., Mejanelle, L., Dachs, J., 2013. Sources, transport and deposition of atmospheric organic pollutants in the Mediterranean sea. ACS Symp. Ser. 1149, 231-260.

R Core Team, 2016. R: A Language and Environment for Statistical Computing. R Foundation for Statistical Computing, Vienna, Austria URL https://www.R-project.org/.

Costantini, D., 2014. Oxidative Stress and Hormesis in Evolutionary Ecology and Physiology: A Marriage Between Mechanistic and Evolutionary Approaches. Springer-Verlag, Berlin Heidelberg, p. 348.

Costantini, D., Dell'Omo, G., 2015. Oxidative stress predicts long-term resight probability and reproductive success in the Scopoli's shearwater (Calonectris diomedea). Conserv. Physiol. 3, cov024.

Costantini, D., Monaghan, P., Metcalfe, N.B., 2011. Biochemical integration of blood redox state in captive zebra finches (Taeniopygia guttata). J. Exp. Biol. 214, 1148-1152.

Costantini, D., Meillere, A., Carravieri, A., Lecomte, V., Sorci, G., Faivre, B., Weimerskirch, H. Bustamante, P., Labadie, P., Budzinski, H., Chastel, O., 2014. Oxidative stress in relation to reproduction, contaminants, gender and age in a long-lived seabird. Oecologia 175, 1107-1116.

Erikstad, K.E., Sandvik, T., Reinertsen, T.K., Bustnes, J.O., Strom, H., 2013. Persistent organic pollution in a high-artic top predator: sex dependent thresholds in adult survival. Proc. R. Soc. Lond. Ser. B 280, 20131483.

Eulaers, I., Covaci, A., Hofman, J., Nygard, T., Halley, D.J., Pinxten, R., Eens, M., Jaspers, V.L.B., 2011. A comparison of non-destructive sampling strategies to assess the exposure of white-tailed eagle nestling (Haliaeetus albicilla) to persistent organic pollutants. Sci. Total Environ. 410, 258e265.

Fenstad, A.A., Jenssen, B.M., Gabrielsen, K.M., Öst, M., Jaatinen, K., Bustnes, J.O., Hanssen, S.A., Moe, B., Herzke, D., Krøkje, A., 2016. Persistent organic pollutant levels and the importance of source proximity in Baltic and Svalbard breeding common eiders. Environ. Toxicol. Chem. 35, 1526-1533.

Fossi, M.C., Casini, S., Marsili, L., Ancora, S., Mori, G., Neri, G., Romeo, T., Ausili, A., 2004 Evaluation of ecotoxicological effects of endocrine disrupters during a four-year survey of the Mediterranean population of swordfish (Xiphias gladius). Mar. Environ. Res. 58, 425-429.

Gómez-Gutiérrez, A., Garnacho, E., Bayona, J.M., Albaigés, J., 2007. Assessment of the Mediterranean sediments contamination by persistent organic pollutants. Environ. Pollut. $148,396-408$

Goutte, A., Barbraud, C., Herzke, D., Bustamante, P., Angelier, F., Tartu, S., Clément-Chastel, C., Moe, B., Bech, C., Gabrielsen, G.W., Bustnes, J.O., Chastel, O., 2015. Survival rate and breeding outputs in a high Arctic seabird exposed to legacy persistent organic pollutants and mercury. Environ. Pollut. 200, 1-9.

Helander, B., Bignert, A., Asplund, L., 2008. Using raptors as environmental sentinels: monitoring the white-tailed sea eagle Haliaeetus albicilla in Sweden. Ambio 37 $425-431$.

International Union for Conservation of Nature and Natural Resources, d. www. iucnredlist.org.

Isaksson, C., 2010. Pollution and its impact on wild animals: a meta-analysis on oxidative stress. EcoHealth 7, 342-350.

Jepson, P.C., Guzy, M., Blaustein, K., Sow, M., Sarr, M., Mineau, P., Kegley, S., 2014. Measuring pesticide ecological and health risks in West African agriculture to establish an enabling environment for sustainable intensification. Philos. Trans. R. Soc. Lond. B 369, 20130491.

Johansson, A.K., Sellstrom, U., Lindberg, P., Bignert, A., de Wit, C.A., 2011. Temporal trends of polybrominated diphenyl ethers and hexabromocyclododecane in Swedish Peregrine Falcon (Falco peregrinus peregrinus) eggs. Environ. Int. 37, 678-686.

Leat, E.H., Bourgeon, S., Magnusdottir, E., Gabrielsen, G.W., Grecian, W.J., Hanssen, S.A., Olafsdottir, K., Petersen, A., Phillips, R.A., Strøm, H., Ellis, S., Fisk, A.T., Bustnes, J.O. Furness, R.W., Borgå, K., 2013. Influence of wintering area on persistent organic pollutants in a breeding migratory seabird. Mar. Ecol. Prog. Ser. 491, 277-293.

Letcher, R.J., Bustnes, J.O., Dietz, R., Jenssen, B.M., Jørgensen, E.H., Sonne, C., Verreault, J., Vijayan, M.M., Gabrielsen, G.W., 2010. Exposure and effects assessment of persistent 
organohalogen contaminants in arctic wildlife and fish. Sci. Total Environ. 408, 995-3043.

Massa, B., Lo Valvo, M., 1986. Biometrical and biological considerations on the Cory's shearwater Calonectris diomedea. In: Monbailliu, M.X. (Ed.), Mediterranean Marine Avifauna. Springer Verlag, Berlin, pp. 293-313.

Müller, M.S., Massa, B., Phillips, R.A., Dell'Omo, G., 2014. Individual consistency and sex differences in migration strategies of Scopoli's shearwaters Calonectris diomedea despite year differences. Curr. Zool. 60, 631-641.

Nordstad, T., Moe, B., Bustnes, J.O., Bech, C., Chastel, O., Goutte, A., Sagerup, K., Trouvé, C. Herzke, D., Gabrielsen, G.W., 2012. Relationships between POPs and baseline corticosterone levels in black-legged kittiwakes (Rissa tridactyla) across their breeding cycle. Environ. Pollut. 164, 219-226.

Northern Presbyterian Agricultural Services, 2012. Ghana's pesticide crisis: a need for further government action. (available online). http://www.christianaid.org.uk/images/ ghanas-pesticide-crisis.pdf.

Paglia, D.E., Valentine, W., 1967. Studies on quantitative and qualitative characterization of erythrocyte glutathione peroxidase. J. Lab. Clin. Med. 70, 158-169.

Quillfeldt, P., Bugoni, L., McGill, R.A.R., Masello, J.F., Furness, R.W., 2008. Differences in stable isotopes in blood and feathers of seabirds are consistent across species, age and latitude: implications for food web studies. Mar. Biol. 155, 593-598.

Roscales, J.L., González-Solís, J., Jiménez, B., 2011. Geographic and trophic patterns of PCBs and DDTs in Mediterranean and NE Atlantic seabirds: can POPs adversely affect Mediterranean seabirds? Organohalogen Compd. 73, 882-885.

Scarpato, A., Romanelli, G., Amici, M., Perini, V., Cozzolino, A., Parravano, R., Piermarini, R. Giordano, P., Azzurro, E., Cento, A., Axiak, V., 2010. Chemical contamination assessment of Malta and Lampedusa coastal waters by means of active mussel watch. Rapp. Comm. Int. Mer Medit. 39, 798.

Schwemmer, P., Covaci, A., Das, K., Lepoint, G., Adler, S., Garthe, S., 2015. Assessment of contaminant levels and trophic relations at a World Heritage Site by measurements in a characteristic shorebird species. Environ. Res. 136, 163-172.

Sebastiano, M., Bustamante, P., Costantini, D., Eulaers, I., Malarvannan, G., MendezFernandez, P., Churlaud, C., Blévin, P., Hauselmann, A., Dell'Omo, G., Covaci, A., Eens,
M., Chastel, O., 2016. High levels of mercury and low levels of persistent organic pollutants in a tropical seabird in French Guiana, the Magnificent frigatebird, Fregata magnificens. Environ. Pollut. 214, 384-393.

Stewart, K.R., Keller, J.M., Templeton, R., Kucklick, J.R., Johnson, C., 2011. Monitoring persistent organic pollutants in leatherback turtles (Dermochelys coriacea) confirms maternal transfer. Mar. Pollut. Bull. 62, 1396-1409.

Tartu, S., Angelier, F., Wingfield, J.C., Bustamante, P., Labadie, P., Budzinski, H., Weimerskirch, H., Bustnes, J.O., Chastel, O., 2015a. Corticosterone, prolactin and egg neglect behavior in relation to mercury and legacy POPs in a long-lived Antarctic bird. Sci. Total Environ. 505, 180-188.

Tartu, S., Lendvai, Á.Z., Blévin, P., Herzke, D., Bustamante, P., Moe, B., Gabrielsen, G.W., Bustnes, J.O., Chastel, O., 2015b. Increased adrenal responsiveness and delayed hatching date in relation to polychlorinated biphenyl exposure in Arctic-breeding blacklegged kittiwakes (Rissa tridactyla). Gen. Comp. Endocrinol. 219, 165-172.

Verboven, N., Verreault, J. Letcher, R. Gabrielsen, G.W., Evans, E. 2009. Differential investment in eggs by Arctic-breeding glaucous gulls (Larus hyperboreus) exposed to persistent organic pollution. Auk 126, 123-133.

Verboven, N., Verreault, J., Letcher, R.J., Gabrielsen, G.W., Evans, E., 2010. Adrenocortical function of Arctic-breeding glaucous gulls in relation to persistent organic pollutants. Gen. Comp. Endocrinol. 166, 25-32.

Verreault, J., Bustnes, J.O., Gabrielsen, G.W., 2010. The Svalbard glaucous gull (Larus hyperboreus) as bioindicator species in the Norwegian Arctic: a review of 35 years of contaminant research. Rev. Environ. Contam. Toxicol. 205, 77e116.

Woolliams, J.A., Wiener, G., Anderson, P.H., McMurray, C.H., 1983. Variation in the activities of glutathione peroxidase and superoxide dismutase and in the concentration of copper in the blood in various breed crosses of sheep. Res. Vet. Sci. 34, 253-256.

Zorita, I., Apraiz, I., Ortiz-Zarragoitia, M., Orbea, A., Cancio, I., Soto, M., Marigómez, I., Cajaraville, M.P., 2007. Assessment of biological effects of environmental pollution along the NW Mediterranean Sea using mussels as sentinel organisms. Environ. Pollut. 148, 236-250. 